\title{
An informational analysis of some comparative psychophysical judgments of apparent sizes
}

\author{
ANTE FULGOSI, GORANKA LUGOMER, and LJERKA FULGOSI \\ Odsjek za psihologiju i Odsjek za pedagogiju, Filozofski fakultet, Zagreb, Yugoslavia
}

\begin{abstract}
Subjects participating in four experimental groups were asked to give judgments about the sizes of areas of squares according to four different psychophysical procedures: absolute judgment, category judgment, ratio estimation, and magnitude estimation. Results were analyzed by the method of informational analysis. Each stimulus was presented in random order 80 times for each experiment. The informational value of the stimulus sets was 4 bits. The median value of the amounts of transmitted information (in bits) for the second half of each experiment was 2.6 for absolute judgments, 2.9 for category judgments, 2.3 for ratio estimation, and 2.9 for magnitude estimation. Based on the results, we concluded that for this kind of stimuli, (1) there is little difference between absolute judgment on one hand and different kinds of comparative judgment on the other; (2) subjects are similarly limited in making quantitative judgments and nominal (identification) judgments; (3) stimulus $\times$ response matrices in psychophysical experiments in which different kinds of comparative judgments are used contain small amounts of information. In such experiments, subjects are able to receive and to handle only a small amount of information contained in stimuli differing in size.
\end{abstract}

Mathematical method of informational analysis, enabling the determination of the amount of information and other informational characteristics, was until now applied to only one kind of psychophysical judgment, the absolute judgment (Garner, 1962; Hake \& Garner, 1951).

In contemporary psychophysics, many other kinds of psychophysical judgments are used. In all of these kinds of judgments, subjects are asked to compare several variable stimuli with one or two standards and to express the experienced magnitudes in relation to these standards. Such judgments are generally known as comparative judgments.

Almost all results and data in modern psychophysics are obtained by methods of comparative judgment, such as magnitude estimation methods, ratio estimation methods, constant sum methods, category estimation methods, partition methods, and so forth. Most important results (e.g., power law) and theories (e.g., sensory transducer theory) of contemporary psychophysics are based on comparative judgments.

Yet, experimental results obtained by the methods of comparative judgments have not been adequately analyzed in terms of their informational characteristics: amount of information they transmit, ambiguity, and channel capacity. The need for informational analysis and the importance of such analysis of comparative judgments is, according to our opinion, obvious.

In addition to the fact that the standard or modulus exists in comparative judgments but not in absolute judgments,

This article is partly based on the results which were presented at the 22nd International Congress of Psychology in Leipzig, July 6-12, 1980. The mailing address of the authors is: Odsjek za psihologiju, Filozofski fakultet, 41000 Zagreb, Yugoslavia. there is another important difference between the two classes of judgment. Absolute judgments, which are nominal and nonquantitative, are used only for the identification of stimuli. Comparative judgments, which are quantitative, are used to determine the size of the differences between the stimuli. It is possible that informational characteristics of comparative judgments are quite different from those of absolute judgments.

In an earlier paper (reported in 1976), several procedures were proposed (A. Fulgosi, 1977) for forming the stimulus $\times$ response matrices for different kinds of comparative judgments in a manner similar to that used to form such matrices for absolute judgments. These procedures allow informational analysis to be applied on the results of experiments using comparative judgment. For each of several kinds of comparative judgment method, the basic stimulus $\times$ response matrix is defined and uniquely determined so that it is possible to apply informational analysis on its content (A. Fulgosi, Lugomer, \& L. Fulgosi, 1980).

In this paper, we report results obtained in experiments in which subjects were asked to make three kinds of comparative judgment in judging the sizes of squares. Informational characteristics (amount of transmitted information) of category estimation procedure, direct estimation of ratios, and magnitude estimation were found and compared with the informational characteristics of absolute judgments of the same stimuli.

\section{METHOD}

\section{Subjects}

In each of the four experiments, 5 different subjects participated. The subjects were students of psychology, randomly assigned to each group. There were 3 females and 2 males in each experimental group. 


\section{Stimuli}

Black squares mounted on wooden boards were used as stimuli. The areas of these squares ranged from $72 \mathrm{~cm}^{2}$ to $625 \mathrm{~cm}^{2}$. Each square was presented in random order 80 times alone (for absolute judgments) or 80 times with the standard stimulus (for comparative judgments). The distance between the subjects and the squares was $4 \mathrm{~m}$.

\section{Procedure}

Absolute judgments. In this experiment, 16 squares with areas ranging from $81 \mathrm{~cm}^{2}$ to $576 \mathrm{~cm}^{2}$ were used. The subjects were instructed to identify each stimulus, using the appropriate number (from 1 to 16), according to its size. Before the beginning of the experiment, all squares were presented to the subjects in order from the smallest to the largest and identified by the experimenter with the appropriate numbers.

Category judgments. In this experiment, there were 16 squares, varying in size from $72 \mathrm{~cm}^{2}$ to $625 \mathrm{~cm}^{2}$, and two standards, a smaller one (which was the next larger than the smallest comparison stimulus and was assigned the number 10) and a larger one (which was the next smaller than the largest comparison stimulus and was assigned the number 40). The two standards were present continuously, and the comparison stimuli were presented in random order between these two standards. The task of the subjects was to compare the apparent size of each (comparison) stimulus with the sizes of the two standard stimuli and to assign each stimulus to one category based on the whole numbers between 5 and 45. Subjects were asked to use equal distances in number values for equal variations in the sizes of the squares.

Ratio estimation. In this experiment, 15 pairs of squares (all possible combinations of 6 squares that ranged in size from $100 \mathrm{~cm}^{2}$ to $625 \mathrm{~cm}^{2}$ ) were presented in random order to subjects. Position of the larger square in each pair was varied randomly. The task of the subjects was to compare the apparent areas of the two squares in each pair and to express their sizes with the adequate ratio of two numbers whose sum must be 100 .

Magnitude estimation. In this experiment, 16 squares that ranged in size from $72 \mathrm{~cm}^{2}$ to $576 \mathrm{~cm}^{2}$ and one standard stimulus (the next larger than the smallest comparison stimulus) were presented to subjects in random order. Each stimulus was exposed side by side with the modulus (standard stimulus). The size of the modulus was assigned the number 10. The task of the subjects was to compare the apparent size of each stimulus with the size of the modulus and to assign to the stimulus a number that reflected its size relative to the size of the modulus. For example, if the stimulus seemed to be two times larger than the modulus, it should be assigned the number 20 .

During each experiment, no feedback was given to the subjects. Each experiment was divided into five sessions.

\section{RESULTS}

The amount of transmitted information for each subject in each experiment was calculated from the first and second halves of each experiment. Median values of the amount of transmitted information and of the amount of input information in each experiment are shown in Table 1.

Table 1

Amounts of Input Information and Transmitted Information in the First (I) and Second (II) Halves of Tasks in Bits and Categories (in Parentheses)

\begin{tabular}{lllll}
\hline & \multicolumn{4}{c}{ Type of Judgment } \\
\cline { 2 - 5 } & Absolute & Category & Ratio & Magnitude \\
\hline Input Information & $4.0(16)$ & $4.0(16)$ & $3.9(15)$ & $4.0(16)$ \\
Transmitted (I) & 2.2 & 2.6 & 1.7 & 2.7 \\
Transmitted (II) & $2.6(6)$ & $2.9(7-8)$ & $2.3(5)$ & $2.9(7-8)$ \\
\hline
\end{tabular}

As in some earlier investigations (A. Fulgosi \& Bartolović, 1971; A. Fulgosi \& Zaja, 1975), we found that in each experiment, the median amount of transmitted information was higher in the second half of the experiment than in the first half. The increases in the amount of transmitted information in the second halves of the present experiments resulted from a decrease in the equivocations in the second halves in each of the four experiments. Response uncertainties were almost the same in both halves of each experiment.

\section{DISCUSSION}

By comparing the amount of transmitted information in each experiment with the amount of given or input information for the respective experiment (Table 1), it can be seen that in each experiment about half of the input information (informational value of the stimulus set) was lost, regardless of the type of psychophysical procedure.

The median values of transmitted information in the second halves of these experiments ranged from 2.3 bits in ratio estimation to 2.9 bits in category judgments and magnitude estimation, showing little difference between these types of psychophysical judgment. The amount of information transmitted in comparative judgments indicates that in judging the sizes of squares, subjects are able to reliably discriminate only eight differences between the standard and variable stimuli. These categories can be called informational intensity categories to distinguish them from the informational categories obtained in absolute judgments.

Our results show that the information transmitted by comparative judgments is only for one category larger, in the case of category judgments and magnitude estimation, and for one informational category smaller, in the case of ratio estimation, when compared with absolute judgments for which the standard stimulus does not exist. It seems that the standard stimulus does not help subjects in making judgments; they are able to judge the differences between two sensations as well as they are able to identify sole sensations.

Our results show that the stimulus $\times$ response matrices that are obtained in psychophysical experiments using comparative judgment procedures generally contain very small amounts of information. This means that subjects in typical psychophysical experiments are unable to receive and consistently handle the information contained in the visual stimuli that are presented to them. In the process of transforming physical energy into physiological energy and judgments, a significant amount of information is lost. It seems also that the sensory system enables subjects to transmit only a limited amount of information about the intensities of visual stimuli included in a set of such stimuli.

\section{REFERENCES}

Fulgosi, A. (1977). Teorija informacije u psihofizici. Stručni skup psihologa DRB 1976. Zagreb: Društvo psihologa Hrvatske.

Fulgosi, A., \& Bartolović, B. (1971). Practice and some methodological problems in unidimensional information transmission. Perception \& Psychophysics, 10, 283-285.

Fulgosi, A., Lugomer, G., \& Fulgosi, L. (1980). Informational characteristics of comparative judgments. Paper presented at the 22nd International Congress of Psychology, Leipzig. (Abstract Guide, p. 118.)

FulgosI, A., \& ŻAJA, B. (1975). Information transmission of 3.1 bits in absolute identification of auditory pitch. Bulletin of the Psychonomic Society, 6, 379-380.

GARNER, W. R. (1962). Uncertainty and structure as psychological concepts. New York: Wiley.

HAKE, H. W., \& GARNER, W. R. (1951). The effect of presenting various number of discrete steps on scale reading accuracy. Journal of Experimental Psychology, 42, 358-366. 